\title{
An IoT Application to Monitor Water Quality
}

\author{
Shazia Muskaan ${ }^{1}$, S.NagaMallik Raj ${ }^{2}$ and S.Neeraja ${ }^{3}$ \\ ${ }^{\text {l} S t u d e n t ~ o f ~ I I I ~ B . T e c h ~ I ~ S e m ~(2017 ~ B a t c h) ~ D e p a r t m e n t ~ o f ~ C o m p u t e r ~ S c i e n c e ~ a n d ~}$ \\ Engineering, Vignan's Institute of Information Technology, Visakhapatnam, India \\ ${ }^{2}$ Asst. Prof, Department of Computer Science and Engineering, Vignan's Institute of \\ Information Technology, Visakhapatnam, India \\ ${ }^{3}$ Asst. Prof, Department of Computer Science and Engineering, Pydah college of \\ Engineering and Technology, Visakhapatnam, India \\ 1shaz.muskaan1123@gmail.com²mallikblue@gmail.com, \\ ${ }^{3}$ neerajasreerama@gmail.com
}

\begin{abstract}
We definitely realize that Water is the most significant asset on earth. It is the substance of all life on earth. But in the event that you ever observe a stream or lake around your city, it is clear to you that we are confronting an intense issue of Water contamination. The international society had given the facts that the $66 \%$ of the Earth's surface is secured by water, seventy-six flawless of your body is comprised of water. As you definitely realize water is all over the place and all around. Be that as it may, we have a fixed measure of water on earth. Nowadays synthetic compounds, microorganisms, and different poisons are notwithstanding influencing our drinking water. The existing methods of water quality testing, whether water is polluted or not, they use manual. By collecting water samples from different locations and these were tested in Labs which takes more time and expensive. So, these older methods were time consuming process and expensive. We proposing IoT based water quality monitoring system by addressing above issues. In this proposed system with the help of sensors we monitor the water quality parameters. So these different sensors will detect the contaminant present in the water and send the report to registered user Mobile smart phone, which is less expensive and Low time consuming.
\end{abstract}

Keywords: IoT, Atmegal6 microcontroller, Banana PI-M64

\section{Introduction}

IoT enables organizations to computerize procedures and get a good deal of work completion. It additionally diminishes waste and improves administration conveyance, making it more affordable to fabricate and convey products and giving straightforwardness into client exchanges. So, with the assistance of IoT we are observing water contaminations and cautioning the people with in brief timeframe.

These days chemicals, bacteria, and other pollutants are even affecting our drinking water. The existing methods of water quality testing, whether water is polluted or not, they uses manual. By collecting water samples from different locations and these were tested in Labs which takes more time and expensive [1]. So, these older methods were time consuming

Article history:

Received (November 19, 2019), Review Result (December 28, 2019), Accepted (February 7, 2020) 
process and expensive. We proposing IoT based water quality monitoring system by addressing above issues. In this proposed system with the help of sensors we monitor the water quality parameters. So, these different sensors will detect the contaminant present in the water and send the report to registered user Mobile smart phone, which is less expensive and Low time consuming.

\section{Purpose}

The main purpose of using IoT for water quality monitoring because there is a communication between the currently considered device model and end system with smart mobile phone. To overcome the drawbacks in manual testing which is time consuming and expensive. Here we collect the water sample into our proposed device, where equipped with different sensors. This was connected to the mobile phone where we can see the result. This IoT based water quality is easy to use and low expensive [2][3].

\section{Methodology}

The major water quality contaminant pollutant was $\mathrm{pH}$, temperature, Chlorine, Total organic carbon and dissolved oxygen.

Step 1: Waste from homes, factories and other buildings get into the water bodies and as a result water gets contaminated we have to collect that contaminated water as samples

Step 2: To detect water quality contaminant pollutant such as $\mathrm{pH}$, temperature, Chlorine, Total organic carbon and dissolved oxygen [4]. For these we use different sensors to detect this pollutant.

Step 3: A smart mobile phone where we can check water quality.

Step 4: All this equipments sensors, end devices, mobile phone were connected to Atmega16 microcontroller.

Step 5: A polluted water samples in Vessels, where sensors were equipped. It detects the percentage of contaminant in that water samples. That result will send to registered mobiles, with the help of Atmega16 microcontroller. Sensor will detect the amount of pollutants present in water, which causes water pollution.

Step 6: this device will send the data to the registered mobile, the details of the amount of pollutants in that water on the spot.

Step 7: Through the mobile, we can know the information, how much water will contaminate with these pollutants.

Step 8: If water is not pollutant, then it is safe to drink.

Step 9: Here we can have clear comparison of the results which is done by manual and using the proposed IOT system. Which are the results were fast and low expensive.

\section{Block Diagram}

The proposed block diagram of IoT based water quality monitoring is given in [Figure 1]. The things needed as follows.

1) Sensor nodes to detect water pollutants

2) One litre vessel

3) Atmega16 microcontroller

4) Banana PI-M64. 
5) Smart phone

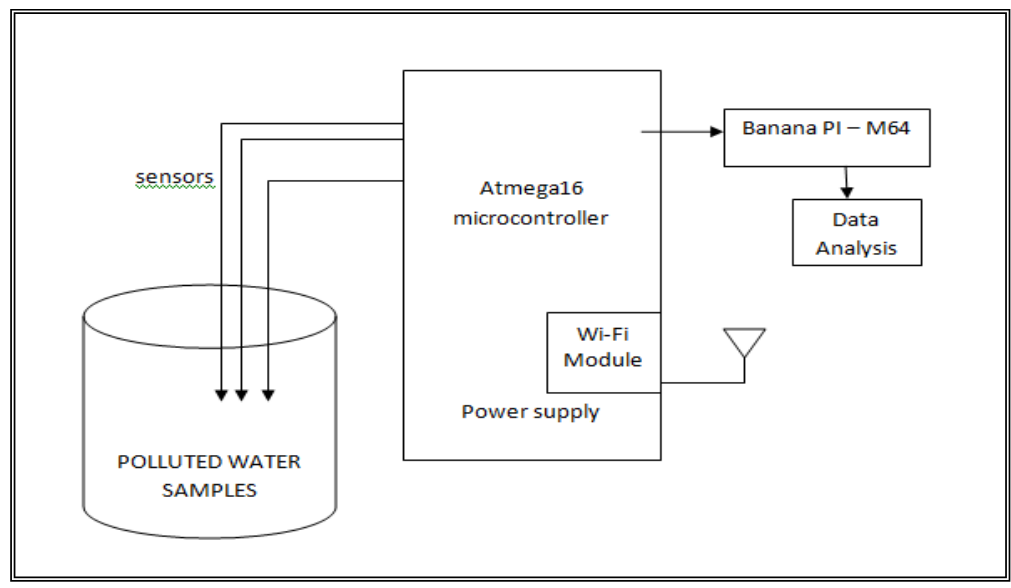

Figure 1. Proposed block diagram of IoT based water quality monitoring.

The physical model of the developed model is given in [Figure 2].

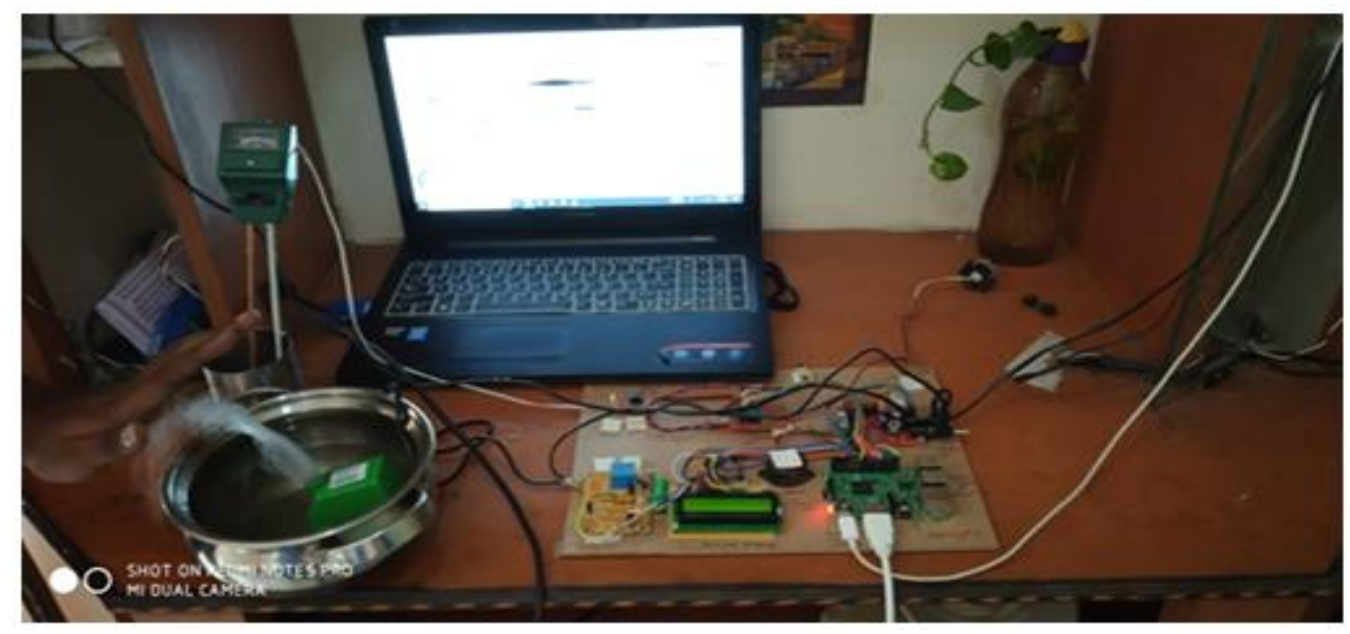

Figure 2. The physical model of the developed water quality model

\subsection{Sensors}

In the proposed framework water quality parameters are estimated by various sensors, for example, $\mathrm{pH}$, temperature and disintegrated oxygen for imparting information onto a stage by means of microcontroller framework [2][4].

(1) Residual Chlorine Senso

Deciding leftover chlorine in water treatment focuses and appropriation frameworks is fundamental and has been significant as long as chlorine has been utilized to sterilize water.

Chlorine sensors assess free chlorine, monochloramine, and all out chlorine. The key application is drinking water sterilization, albeit all out chlorine is likewise frequently surveyed in treated wastewater.

(2) TOC Sensor 
All out natural carbon (TOC) is both an immediate pointer and a surrogate is a pivotal parameter for water quality assessment. There are two sorts of TOC sensors right now accessible: TOC analyzers and TOC sensors.

Whenever utilized for administrative detailing, administering a fundamental procedure control variable or quality control, instrument unwavering quality is vital. Whenever utilized for general TOC following - not for settling on significant quality choices, at that point other sensor characteristics might be more basic than precision.

\section{(3) Turbidity Sensor}

Turbidity sensors check suspended solids in water, regularly by deciding the measure of light that can go through the water. These sensors are utilized in waterway and stream testing, wastewater estimations, drinking water treatment tasks, settling lakes the executives, residue transport study and research center testing.

\section{(4) Conductivity Sensor}

Conductivity testing is regularly led in mechanical settings to acquire information on absolute ionic focuses, for example, the measure of broke up mixes, in fluid arrangements. Basic applications incorporate water decontamination, clean set up (CIP) control, and estimating focus sums in arrangements.

A standard conductivity sensor can be either an inline sensor straightforwardly embedded or a sensor in a lodging, with a link connected to a transmitter, which sends sign to a handling as well as chronicle gadget.

(5) $\mathrm{pH}$ Sensor

The $\mathrm{pH}$ of an answer, how acidic or fundamental it is, a noteworthy marker of water quality. Sensors used to decide $\mathrm{pH}$ are normally a solitary terminal, ordinarily made of glass and very sensitive. A terminal is normally joined to an analyzer that has an interface for information gathering, alignment, and cautions.

(6) ORP Sensor

ORP sensors measure the Oxygen-Reduction Potential of a water test. Utilized related to a $\mathrm{pH}$ sensor, an ORP estimation can offer understanding into the level of oxidation/decrease responses occurring in the arrangement. An ORP Sensor ought to be associated with a powerful interface and programming to assemble information.

\subsection{Atmega16 microcontroller}

Description of Block Diagram The research paper is soldered by making the microcontroller at the centre. The sensors and communication devices are connected to the microcontroller [5].

(1) Microcontroller

The brain of the current model which controls the overall activities. All devices are connected to it by using wires. The research paper uses Atmega16 microcontroller.

(2) Communication devices

They serve as a bridge between the microcontroller and the user. They are crucial for this research paper. Without the communication with the user, we can't say that the system is working. 


\section{(3) GSM}

Sending and receiving of SMS between the user and the microcontroller.

\subsection{The Banana Pi M-64}

The Banana Pi M-64 was a quad-centre 64-piece SBC highlights which had 2GB of RAM and an $8 \mathrm{~GB}$ of eMMC module. WiFi and Bluetooth are implicit and there is a couple of USB 2.0 hosts, a USB OTG, and HDMI yield. Accessible BananaPi M64 OS choices incorporate Windows 10 IoT Core, Android, Linux, and Free BSD. Its a muscular creator board equipped for some ventures. Eminently, the users should seriously think about the Banana Pi R2 too which can be utilized as a DIY switch or NAS.

\section{Results}

The results obtained after implementing the current model for checking the quality of the water are shown as follows.

\subsection{Ground water}

Final results for ground water are as follows $\mathrm{pH}$ : 08, Temperature: 29, Turbidity: 05 and this water is not good for drinking purpose. The $\mathrm{pH}$ value is not up to the quality parameters.
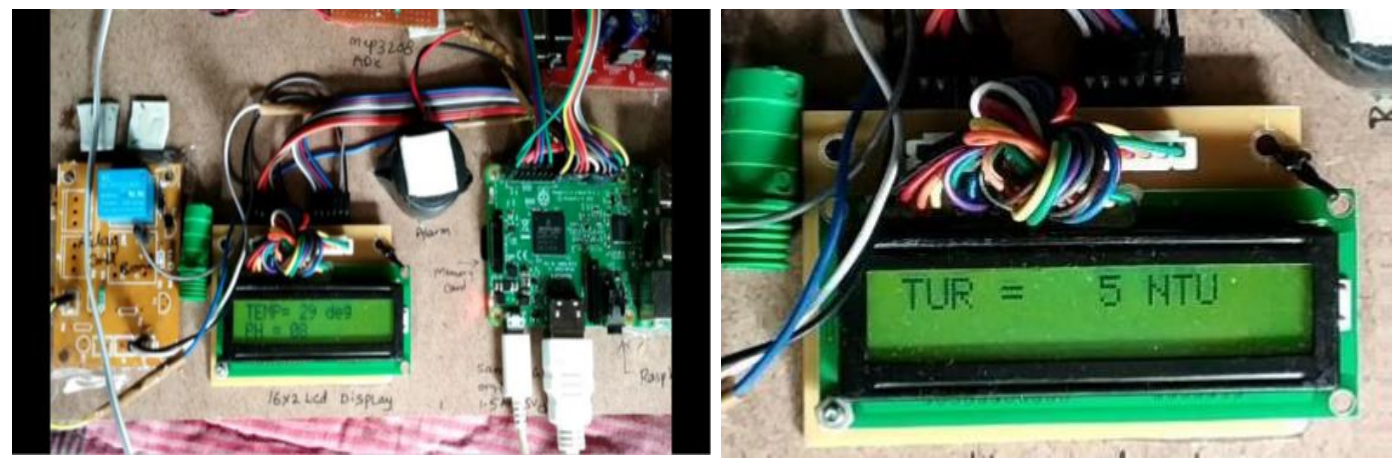

Figure 3. The output values generated for ground Water

\subsection{Rain water}

As the currently considered project had implemented for two cases of different cases with rain water and ground water and the results are shown in the figures above at [Figure 3] and [Figure 4].
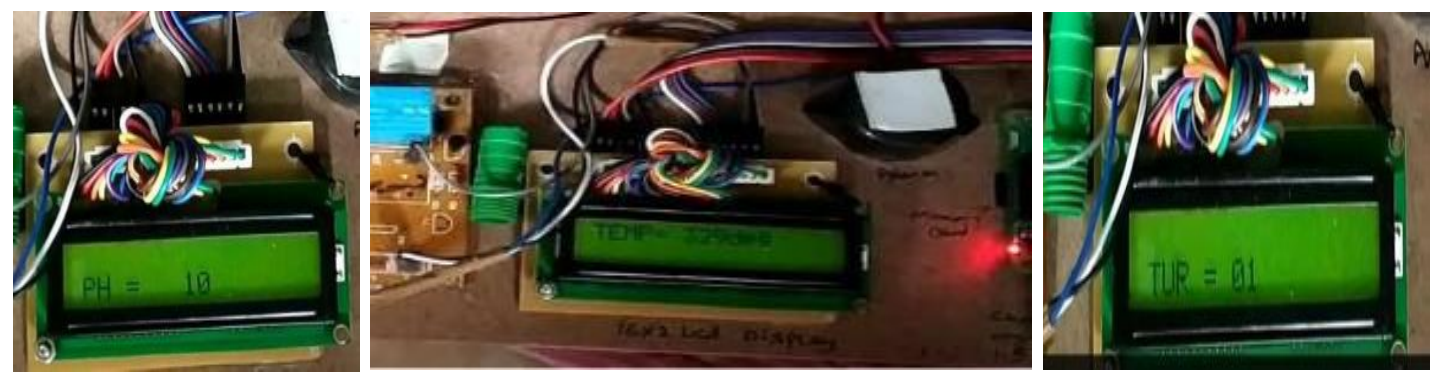

Figure 4. The output values generated for Rain Water 


\section{Conclusion}

This IOT application will clarify many doubts to people while they were consuming the water, it gives result on the spot water is polluted or not., It gives details which type of pollutants present in the water. This entire process will be seen in our mobile. After observing result. So, within few minutes the entire process will be done on our hand (one litre vessel equipped with the device. This device will run with the help of battery. This equipment will be more helpful when we are travelling to any place, if we want to consume water which is available there, this device will test and it will say "Water is SAFE or NOT".

\section{Future scope}

In this proposed system we can check only whether water is polluted or not. If it is polluted how much ratio of pollutants were present in water. But in future we are going to do research on not only monitor we can also purify the water there itself. So the device equipped with both detecting and purifying the pollutants present in water.

\section{References}

[1] N Vijayakumar and R Ramya, "The Real Time Monitoring of Water Quality in IOT Environment," International Conference on Circuit, Power and Computing Technologies, IEEE Transactions on Networks, vol.16, pp.25-33, (2017) DOI: 10.1109/ICIIECS.2015.7193080

[2] A.N. Prasad, K.A. Mamun, F.R. Islam, and H. Haqva, "Smart water quality monitoring system," IEEE Transactions on Networks, vol.10, pp.35-43, (2015) DOI: 10.1109/APWCCSE.2015.7476234

[3] Wind River, "Security in the internet of things - Lessons from the past for the Connected future," WIND River, Accessed Dec 17, (2016)

[4] Young Hua Ling, Jiabin Tang, Qing Yang, and Chao Zui, "Wireless Communication for IOT(Internet of Things)", IBM Research. Accessed December 17, (2016)

[5] N.Thirupathi Rao, Debnath Bhattacharyya, V. Madhusudana Rao and Tai-Hoon Kim, "Water Quality Testing and Monitoring System”, International Journal of Innovative Technology and Exploring Engineering, vol.8, no.5, pp.162-166, (2019) 